\title{
Integrating Intermittent Renewable Wind Generation - A Stochastic Multi-Market Electricity Model for the European Electricity Market
}

\author{
Jan Abrell • Friedrich Kunz
}

Published online: 17 December 2014

(C) Springer Science+Business Media New York 2014

\begin{abstract}
In northern Europe, wind energy has become a dominate renewable energy source, due to natural conditions and national support schemes. However, the uncertainty about wind generation affects existing network infrastructure and power production planning of generators, which cannot be fully diminished by wind forecasts. In this paper we develop a stochastic electricity market model to analyze the impact of uncertain wind generation on the different electricity markets as well as network congestion management. Stochastic programming techniques are used to incorporate uncertain wind generation. The technical characteristics of transporting electrical energy as well as power plants are explicitly taken into account. The consecutive clearing of the electricity markets is incorporated by a rolling planning procedure reflecting the market regime of European markets. The model is applied to the German electricity system covering one week. Two different approaches of considering uncertain wind generation are analyzed and compared to a deterministic approach. The results reveal that the flexibility of generation dispatch is increased either by using more flexible generation technologies or by operating rather inflexible technologies under part-load conditions.
\end{abstract}

Keywords Electricity markets · Unit commitment - Stochasticity · Renewable energy $\cdot$ Transmission network

\footnotetext{
J. Abrell ( $\square)$

Swiss Federal Institute of Technology Zurich, Center for Energy Policy and Economics at ETH Zurich, Zürichbergstrasse 18, CH-8032 Zürich, Switzerland

e-mail: jabrell@ethz.ch

F. Kunz

Department of Energy, Transportation, Environment, German Institute for Economic Research (DIW Berlin), Mohrenstraße 58, 10117 Berlin, Germany

e-mail: fkunz@diw.de
} 


\section{Introduction}

Electric power industries in Europe have experienced a major restructuring process toward a competitive market environment in which generators face the fundamental task of determining the optimal dispatch of their thermal power plants. In contrast to former monopolistic times, generators now have to recover their costs solely through prices determined in different electricity markets: In a dayahead market, generators offer supply of electricity for all hours of the subsequent day. In the intraday market these offers can be continuously revised reacting to new information available in the market. Finally, the transmission system operator (TSO) needs to ensure that electricity supply announced by the generators is feasible, i.e., the TSO has to ensure reliability of electricity supply.

On the other hand, concerns about climate change initiated an ongoing transformation of the electricity system toward less carbon-intensive generation technologies. Therefore, several European countries have implemented special support schemes for renewable energy sources in order to, firstly, not just reduce domestic carbon dioxide emissions but also fossil fuel import dependency in the energy sector. In this context, wind energy, among others, has become a dominating renewable source due to favorable natural conditions, technological progress, and political support. For instance, between 2000 and 2010, 75 GW wind capacity was installed in Europe, resulting in a share of $10 \%$ in the European power capacity mix (EWEA 2011). However, wind generation is characterized by a variable and uncertain generation pattern as it directly depends on meteorological conditions. Hence, it cannot be dispatched in a controlled manner like conventional power plants. Consequently, variability and uncertainty about the residual load left to conventional dispatchable generation technologies is increasing, which imposes additional integration costs as the balance between demand and supply needs to be ensured at every instant of time by conventional generation technologies.

In this article, we develop a quantitative framework mimicking the subsequent clearing of different electricity markets. Special emphasis is put on the role of physical restrictions imposed by the electricity transmission system and the intermittent nature of wind power. Furthermore, the framework is applied to assess the impacts of different electricity markets against a hypothetical benchmark of integrated planning. Moreover, we evaluate the costs of intermittent wind power and its dependency on the modeling approach to uncertainty. We find that employing a stochastic programming approach lowers system costs compared to deterministic optimization based on expected values. This is achieved by creating flexibility in the generation mix in two ways: first, using traditional flexible gas-fired technologies. Second, operating rather inflexible coal-fired plant in part-load creates the flexibility to increase generation in the short-run avoiding additional startup of capacity.

To address the complex interactions in electricity systems, unit commitment and economic dispatch approaches are applied to determine a secure and economically optimized generation scheduling. As most electricity systems are dominated by thermal generation capacities, the aim of the short-term planning is to determine the 
least-cost generation mix of different technologies to meet a specified electrical load taking into account operational limitations of thermal units, i.e., minimum ontime, minimum offtime, and ramping constraints. ${ }^{1}$ As the variability and uncertainty of renewable generation influences the short-term operation of the electricity system, elements of stochastic optimization have been introduced into the unit commitment framework. ${ }^{2}$ Recently, a variety of contributions focus on the large-scale integration of renewable wind generation in power systems and both their short- and long-term implications on the electricity system. In the long-term, the appropriate development of transmission as well as generation infrastructure has to ensure a secure and efficient integration of renewable energy sources (e.g. Traber and Kemfert 2011; Weijde and Hobbs 2012; Spiecker and Weber 2014). Regarding the short-term implications, the variability and uncertainty inherent in wind generation is a dominating aspect affecting, in particular, the unit commitment of thermal generation units. Most studies generally focus on optimal unit commitment strategies under stochastic wind generation within a two-stage framework consisting of first-stage unit commitment and a second-stage dispatch (e.g. Bouffard and Galiana 2008; Wang et al. 2008; Ruiz et al. 2009; Pritchard et al. 2010; Wang et al. 2011; Papavasiliou and Oren 2013). While the incorporation of uncertainty generally leads to an increase of system costs, the unit commitment and dispatch of power plants is more robust to short-term fluctuations of intermittent generation, which then can reduce the need for dayahead reserve procurement. However, the structure of the underlying market regime is often condensed to two stages reflecting dayahead and real-time decisions, whereas most market regimes, i.e. Germany, are characterized by a subsequent clearing of daily dayahead and hourly intraday electricity markets. Thus, using a two-stage setting abstracts from the fact that forecasts as well as, henceforth, commitment and dispatch decisions are revised during the day (Papavasiliou and Oren 2013). Within a multi-market setup, the interaction of revised renewable generation forecasts, which improve over time, and the flexibility of committed generation can be explicitly considered. On the one hand, renewable generation forecasts become more accurate closer to real-time. On the other hand, conventional generation is less flexible closer to real-time due to unit commitment restrictions. This trade-off is important to consider when investigating integration aspects of uncertain renewable generation.

\footnotetext{
${ }^{1}$ Baldick (1995) provides a generalized formulation of the unit commitment problem; a recent review of various contributions to the unit commitment literature is given in Padhy (2004).

${ }^{2}$ Stochastic models allow for an explicit representation of the sources of uncertainty reflected through multiple scenarios with associated probabilities, whereas in deterministic optimization models all input parameters are assumed to be certain or deterministic. Fundamentals of stochastic optimization can be found in Birge and Louveaux (1997) and Kall and Wallace (1994). With respect to energy, Wallace and Fleten (2003) provide a survey of different stochastic programming models and their application to the energy sector. Herein, stochastic versions of the unit commitment, generation dispatch, as well as optimal power flow are presented and solution methods are discussed. Additionally, an overview of different applications of stochastic programming with a focus on electricity systems is given in Weber (2005), Kallrath et al. (2009), Möst and Keles (2010), and Conejo et al. (2010).
} 
The successive clearing of the dayahead and intraday markets, as well as the improvement in renewable forecasts is incorporated in Weber et al. (2009). They formulate a stochastic programming model to assess the impact of large-scale wind power generation on electricity systems. A rolling planning procedure is implemented to link the different electricity markets. ${ }^{3}$ The stochastic behavior of wind generation is explicitly taken into account and the model thus allows the assessment of the impact of increased wind generation on reserve needs and usage, power plant operation and system costs. Tuohy et al. (2009) present an updated version of Weber et al. (2009), including a mixed-integer unit commitment. However, both approaches have in common that they abstract from the physical characteristics of electricity flows and the management of congestion by the transmission system operator. In other words, congestion in the physical transmission network which may influence the utilization of thermal as well as renewable capacities is not considered. The management of network congestion is particularly important with increasing renewable capacities (Kunz 2013; Neuhoff et al. 2013). ${ }^{4}$ With respect to electricity transmission, Leuthold et al. (2012) describe a deterministic techno-economic model with a detailed representation of the European high voltage network. Physical characteristics of power transmission are represented by a DC-loadflow approach. In various applications, the impact of wind power generation on the power system, in particular on the physical transmission network, are analyzed (e.g. Leuthold et al. 2009; Weigt et al. 2010), but mostly abstracting from a detailed market representation. The approach presented in this paper combines the characteristics of the different electricity markets as well as the technical specifics of thermal generation with the characteristics of transmitting electricity. Thus, the main contribution of this paper lies in the combination of these two characteristics into one modeling framework. Additionally, the intermittency of wind generation is explicitly taken into account by employing stochastic programming techniques.

In this paper we describe a stochastic Electricity Market Model (stELMOD), which is used to investigate the impact of stochastic wind generation on the unit commitment and dispatch of power plants taking into account limitations through physical network congestion. The successive market-clearing process of dayahead and intraday markets is rebuilt considering the arrival of improved information on wind generation forecasts in each optimization step. After clearing of the daily dayahead and the subsequent hourly intraday markets, the final power plant dispatch is determined by the transmission system operator considering network congestion arising from previous market commitments. Uncertainty about wind generation is represented by a two-stage multi-period scenario tree and updated for each intra-

\footnotetext{
${ }^{3}$ Devine et al. (2014) applies a similar concept to replicate the clearing of the UK natural gas markets considering stochastic demand.

${ }^{4}$ Moreover, the economic relevance of transmission networks in electricity systems is not limited to the short-term congestion perspective. Jonkeren et al. (2014) investigate the impact of critical infrastructure failures and develop a modeling framework to quantify the economic implications. Furthermore, Abrell and Weigt (2012) analyze the interaction effects between different energy infrastructures. They show that the interaction of congestion in electricity transmission and natural gas pipeline networks can lead to unexpected consequences of energy regulation.
} 
day market optimization. Our general modeling framework resembles Tuohy et al. (2009). In contrast to Tuohy et al. (2009) we incorporate an explicit representation of transmission flows and congestion management based on Kunz (2013). A DC-loadflow approach is used to determine physical electricity flows in the interconnected transmission network. The model is applied to the German electricity system covering a time frame of 168 hours (one week) in order to investigate the impacts of stochastic wind power availability on the German electricity system. We further contribute to the existing literature by evaluating the effects of a rolling planning approach compared to an integrated central planning perspective.

The remainder of the paper is structured as follows. In the next section we briefly describe the daily market procedure of the German electricity market. Based on this framework, three distinct models - a dayahead market, an intraday market, and a congestion management model - are developed and coupled by a rolling planning procedure to reflect the subsequent market clearing. Section 3 presents the data used including the derivation of wind generation forecasts. In Section 4, we compare different approaches of incorporating stochastic supply of wind power to a deterministic case. Furthermore, we evaluate the effects of rolling planning procedure compared to an integrated approach which is optimized over the whole time horizon. Section 5 formulates the conclusions.

\section{Model}

\subsection{Daily German Electricity Market Procedure}

In this section, we briefly describe the typical daily market procedure of the German electricity system, which is comparable to other Western European countries. In general, the market approach relies on a decentralized structure in which market participants are responsible to plan the commitment of their generation and load facilities. Market participants voluntarily interact either on a bilateral basis or on standardized market platforms and, thus, are not obliged to participate in either of them. In the following, we concentrate our analysis on the standardized markets as they can be interpreted as a benchmark for other trading opportunities. The electricity market can be divided into four sub-markets namely the futures or forward market, dayahead or spot market, the intraday market, and the reserve market. We are particularly interested in the latter three markets and therefore abstract from futures and forward markets. In the case of Germany, the dayahead and the intraday markets are organized by the EPEX in Paris, whereas the reserve market is jointly organized by the four German transmission system operators. Contrasting to other market design, the German as well as other European markets account only for international transmission capacity limitations within the markets while the congestion management on national transmission lines is conducted by the corresponding transmission system operators after the last market clearing.

Following Fig. 1, the typical daily market procedure is as follows: The dayahead market is cleared at 12.00 a.m. dayahead (D-1) following the clearing of the market for tertiary reserve. The dayahead market comprises a daily auction for all 24 hours of 


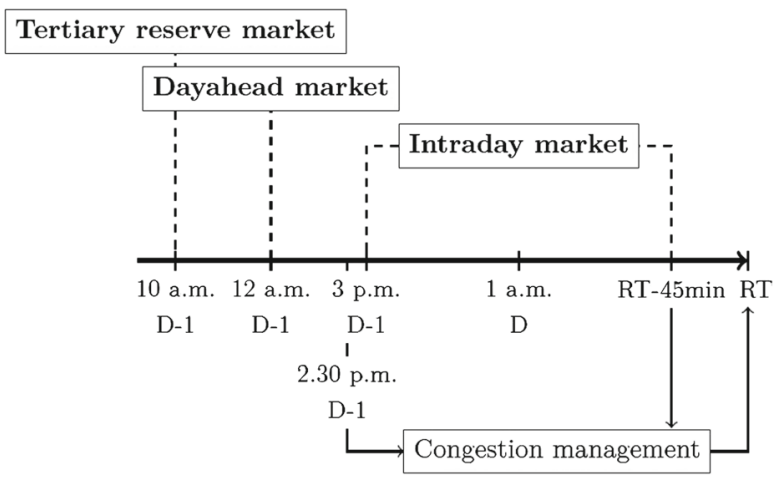

Fig. 1 Daily market procedure of the German electricity market (schematic representation)

the following day (D). Based on the contractual obligations determined in the dayahead market, generators have to inform the responsible transmission system operator of their proposed dispatch timetable at 2.30 p.m. dayahead. Subsequently, the intraday market starts at 3.00 p.m. and is closed 45 minutes before real-time or physical delivery. Market participants can trade electricity continuously, either standardized through the market platform provided by EPEX or on a bilateral basis. Generators are afterwards obliged to deliver their final dispatch timetables for each 15 minute interval to the corresponding transmission system operator 45 minutes prior to real time at the latest. Based on these dispatch timetables, the transmission system operators are in charge of performing congestion management in the event physical network limitations occur. For this purpose, transmission system operators can generally make use of technical and market-based methods. Active loadflow management can be done technically through adjustments of network topology (e.g. switching actions) and network characteristics (e.g. changes of transformer taps). On the other hand, marketbased congestion management methods comprise the adjustment of nodal generation or load (e.g. re-dispatch or counter-trading). Finally, close to or at real-time transmission system operators activate precontracted reserve capacities to compensate for deviations between realized load and generation.

In order to represent the daily timing of the German electricity market we use three different models ${ }^{5}$ : In the dayahead model, the system operator decides about the quantities of electricity and reserve delivered on the next day based on the expected renewable generation supply and the current status of power plants. In the intraday model, the operator takes these quantities as given. Based on new information about the renewable supply he has the possibility to correct the pre-contracted electricity quantities by trading in the intraday market. Lastly, flows in the transmission network are determined and arising line overloadings are managed by the transmission system operator in the congestion management model. The models are combined in a rolling

\footnotetext{
${ }^{5}$ We assume perfectly competitive market, thus abstracting from any strategic behavior. E.g. Metzler et al. (2003) and Habis and Csercsik (2014) incorporate different fashions of strategic behavior of generators and load in network-constrained electricity markets.
} 
planning procedure which passes the pre-contracted quantities as well as the plant status between the models. In the next subsections, we describe the three models as well as the rolling planning approach in detail.

\subsection{Dayahead Market Model}

In the dayahead model, the system operator decides about the generation and contribution to reserve requirements of thermal power plants $p \in P^{6}$, pump storage plants $j \in J$, and renewable sources $w \in W$ in order to minimize the total system operating costs for a specified time horizon $T$. Generation of thermal power plants in period $t \in T$ is denoted by $G_{p, t}$, contribution to reserve market $r \in R$ by $R_{p, r, t}^{+}$and $R_{p, r, t}^{-}$ depending on whether it is upward or downward reserve, and the plant status by $U_{p, t}$, which becomes one if the plant is online and zero else. Thermal power plants are characterized by their marginal generation costs $c_{p}$ and costs that occur if the plant is started or shut down, $c_{p}^{s}$ and $c_{p}^{d}$, respectively. The installed capacity is given by $g_{p}^{\text {max }}$. The minimum generation is denoted by $g_{p}{ }_{p}^{\text {min }}$ and has to be committed if the plant is online. Furthermore, power plants have to fulfill technical requirements in the form of minimum offline and online time requirements: a plant has to remain online for the next $t_{p}^{\text {on }}$ time periods after start up. Similarly, $t_{p}^{\text {off }}$ denotes the minimum time periods the plant has to be offline after shut down.

In addition to thermal power plants, the model includes pump storage facilities. The release or generation of these facilities is denoted by $V_{j, t}$ and pumping or withdrawal by $W_{j, t}$. Both the generation and pumping of the storage facilities are upper bounded by the turbine $v_{j}^{\max }$ and pump capacity $w_{j}^{\max }$, respectively. The pumping process causes losses expressed by the round-trip efficiency $\eta_{j} \in$ ]0, 1]. Furthermore, the storage capacity $l_{j}^{\text {max }}$ limits the level of the storage facility $L_{j, t}$. The reserve contribution of storage facilities is denoted by $R_{j, t}^{H+}$ and $R_{j, t}^{H-}$, respectively.

Renewable sources are denoted by $w \in W$ and comprise of solar and wind technologies. In the dayahead model, there is a unique renewable generation forecast $\bar{s}_{w, t} .7$ The generation of renewable sources $S_{w, t}$ is equal to this forecast reduced by the amount of renewable supply curtailed $C_{w, t}$. The marginal generation costs are assumed to be zero. The curtailment of renewable sources causes a penalty payment $c_{w}^{C}$ to reflect the prioritized feed-in of these sources.

\footnotetext{
${ }^{6} \mathrm{~A}$ list of the notation used is given in the appendix.

${ }^{7}$ It is important to note that a deterministic dayahead market setup may underestimate the effects of an equivalent stochastic setup. However, a unique dayahead renewable forecast is assumed for two reasons: from a market perspective, marketers of renewable energy have to place a bid in the dayahead market specifying the deliverable amount of electricity. Therefore, the amount of renewable energy may be based on an evaluation of underlying uncertainties, but the offered amount itself is then deterministic. Moreover, from a methodological perspective, the incorporation of uncertain renewable generation in a stochastic modeling setup requires the specification of technology-specific recourse costs for adjusting the first stage decision. These costs may be higher than the direct marginal generation costs due to additional transaction costs as corrective bidding may be required in the intraday market.
} 
The geographical location of load and generation is incorporated by a set of nodes reflecting electrical substations $n \in N$ that belong to a specified country $c \in C$. The relationship of nodes and countries is specified in the set $\Upsilon \subset N \times C$. The exchange of electricity between adjacent countries $T_{c, c c, t}$ is restricted by the net transfer capacity $n t c_{c, c c}$. The locational characteristics of thermal power plants, storage facilities, and renewable sources is expressed using the two-dimensional set $\Psi \subset(P \cup J \cup W) \times N$, meaning that if plant $p$ is located at node $n$ then $(p, n) \in \Psi$.

The load at node $n$ in period $t$ is given by $d_{n, t}$. We assume a fixed and, thus, price-inelastic load that needs to be served by the generation technologies. Additionally, we include the possibility to account for different reserve markets in the model. The reserve markets are denoted by $r \in R$ and are characterized by a country-specific positive and negative reserve load $d r_{c, r, t}^{+}$and $d r_{c, r, t}^{-}$. Depending on the technical pre-qualification requirement of the reserve market, thermal power plants and storage facilities are allowed to contribute to these markets. These pre-qualification requirements are expressed via the two-dimensional set $A \subset(P \cup J) \times R$.

$$
\begin{aligned}
& \min \sum_{t, p}\left[c_{p} G_{p, t}+C S_{p, t}+C D_{p, t}\right] \\
& +\sum_{t, w} c_{w}^{C} C_{w, t} \\
& C S_{p, t} \geq c_{p}^{s}\left(U_{p, t}-U_{p,(t-1)}\right) \\
& C D_{p, t} \geq c_{p}^{d}\left(U_{p,(t-1)}-U_{p, t}\right) \\
& \sum_{n} d_{n, t}=\sum_{p} G_{p, t} \\
& +\sum_{j}\left(V_{j, t}-W_{j, t}\right)+\sum_{w} S_{w, t} \\
& \sum_{n \in \Upsilon(c)} d_{n, t}=\sum_{p \in \Psi(\Upsilon(c))} G_{p, t} \\
& -T_{c, c c, t}+T_{c c, c, t} \\
& +\sum_{j \in \Psi(\Upsilon(c))}\left(V_{j, t}-W_{j, t}\right)+\sum_{w \in \Psi(\Upsilon(c))} S_{w, t} \\
& d r_{c, r, t}^{+}=\sum_{p \in(A(r) \cap \Psi(\Upsilon(c)))} R_{p, r, t}^{+}+\sum_{j \in(A(r) \cap \Psi(\Upsilon(c)))} R_{j, r, t}^{H+} \quad \forall c, r, t \\
& d r_{c, r, t}^{-}=\sum_{p \in(A(r) \cap \Psi(\Upsilon(c)))} R_{p, r, t}^{-}+\sum_{j \in(A(r) \cap \Psi(\Upsilon(c)))} R_{j, r, t}^{H-} \quad \forall c, r, t
\end{aligned}
$$




$$
\begin{aligned}
& U_{p, t} g_{p}^{\max } \geq G_{p, t}+\sum_{r} R_{p, r, t}^{+} \\
& G_{p, t}-\sum_{r} R_{p, r, t}^{-} \geq U_{p, t} g_{p}^{\text {min }} \\
& U_{p, \tilde{t}} \geq U_{p, t}-U_{p,(t-1)} \\
& 1-U_{p, \tilde{t}} \geq U_{p,(t-1)}-U_{p, t} \\
& L_{j, t}=L_{j,(t-1)}+\eta_{j} W_{j, t}-V_{j, t} \\
& w_{j}^{\max } \geq W_{j, t}+\sum_{r} R_{j, r, t}^{H-} \\
& v_{j}^{\max } \geq V_{j, t}+\sum_{r} R_{j, r, t}^{H+} \\
& l_{j}^{\max } \geq L_{j, t}+\sum_{r} R_{j, r, t}^{H-} \\
& S_{w, t}=\overline{s_{w, t}}-C_{w, t} \\
& \forall p, t \\
& \forall p, t \\
& \forall p, t, \tilde{t} \in O_{p, t}^{o n} \\
& \forall p, t, \tilde{t} \in O_{p t}^{o f f} \\
& \forall j, t \\
& \forall j, t \\
& \forall j, t \\
& \forall j, t \\
& \forall w, t \quad(16) \\
& n t c_{c, c c} \geq T_{c, c c, t} \\
& \forall c, c c, t \\
& G_{p, t}, V_{j, t}, W_{j, t}, L_{j, t}, C_{w, t}, T_{c, c c, t}, C S_{p, t}, C D_{p, t}, R_{p, r, t}^{+}, R_{p, r, t}^{-}, R_{j, r, t}^{H+}, R_{j, r, t}^{H-} \geq 0 \\
& U_{p, t} \in\{0,1\}
\end{aligned}
$$

The objective function 1 of the dayahead model minimizes the sum of the marginal, startup $C S_{p, t}$, and shutdown $C D_{p, t}$ costs as well as the renewable curtailment penalty payment. The startup and shutdown costs are defined in Eqs. 2 and 3 in terms of a change of the plant status variable. The market clearing (4) equates the total load and supply in the market. In contrast, the country based market clearing (5) equates load and supply at nodes located in country $c$. This equation is necessary to define the trade variable $T_{c, c c, t}$. Equations 6 and 7 ensure the provision of the reserve requirements. Equations 8 and 9 implement the minimum and maximum generation constraints. Equations 10 and 11 are the minimum online and offline time requirements. For the ease of notation, we introduced the sets $O_{p, t}^{o n}:=\left\{t+1, \cdots, \min \left[t+t_{p}^{o n}, T\right]\right\}$ and $O_{p, t}^{\text {off }}:=\left\{t+1, \cdots, \min \left[t+t_{p}^{\text {off }}, T\right]\right\}$, which define the periods in which the plant has to be online and offline. Equation 12 is the law of motion for the reservoir level of storage facilities. The restrictions on the pumping and release processes as well as the reservoir levels are given in Equations 13 to 15 . The supply of renewable energy sources $S_{w, t}$ is defined in Eq. 16 in terms of the exogenously given supply and the curtailed amount. Equation 17 restricts the commercial transfers between adjacent countries to stay within the transfer limit $n t c_{c, c c}$.

\subsection{Intraday Market Model}

The intraday model is similar to the dayahead model in terms of technical restrictions for thermal plants and storage facilities. However, in this model the pre-contracted 
generation quantities and reserve contributions are provided by the dayahead model. In order to express the pre-determined character of the given variables we denote them with upper bars, i.e., $\overline{G_{p, t}}, \overline{V_{j, t}}, \overline{W_{j, t}}$, and $\overline{C_{w, t}}$ are the fixed generation, pumping, release and curtailment variables determined in the dayahead market. The reserve quantities are denoted in the same manner, i.e. $\overline{R_{p, r, t}^{+}}, \overline{R_{p, r, t}^{-}}, \overline{R_{j, r, t}^{H+}}$, and $\overline{R_{j, r, t}^{H-}}$. These are contracted in the dayahead market and fixed in subsequent intraday markets. In the intraday market, the system operator has the possibility to correct these quantities by additional trading actions. Due to the corrective character of these variables, they are free in sign, i.e. the operator can increase or decrease the amount sold in the dayahead market. We maintain the notation, but denote the intraday variable by a tilde sign. Given these notations, the total generation in the intraday market is defined as the sum of the pre-determined dayahead quantity and the corrective intraday action.

As the second major difference between the dayahead and intraday market model, we explicitly introduce the stochastic generation of renewable sources supply by introducing a scenario tree. This tree represents the underlying stochastic process by a set of nodes, $k \in K$, that belong to a certain period. We denote the subset of nodes that belong to period $t$ by $\Omega_{t} \subset K$. The probability of reaching node $k$ is given by $\pi_{k} \in[0,1]$. Except for the root node, each node has a unique predecessor node that is denoted by $\gamma(k)$. Furthermore, the set of all nodes in the route from the root node to node $k$ is denoted by the ordered set $\Gamma(k) \subset K$. With this notation at hand, the intraday model becomes: ${ }^{8}$

$$
\begin{array}{ll}
\min \sum_{k, t, p} \pi_{k}\left[c_{p} G_{p, k, t}+C S_{p, k, t}+C D_{p, k, t}\right] & \\
+\sum_{k, t, w} \pi_{k} c_{w}^{C} C_{w, k, t} & \\
G_{p, k, t}=\overline{G_{p, t}}+\tilde{G}_{p, k, t} & \\
V_{j, k, t}=\overline{V_{j, t}}+\tilde{V}_{j, k, t} & \forall p, t, k \in \Omega_{t} \\
W_{j, k, t}=\overline{W_{j, t}}+\tilde{W}_{j, k, t} & \forall j, t, k \in \Omega_{t} \\
C_{w, k, t}=\overline{C_{w, t}}+\tilde{C}_{w, k, t} & \forall j, t, k \in \Omega_{t} \\
C S_{p, k, t} \geq c_{p}^{s}\left(U_{p, k, t}-U_{p, \gamma(k),(t-1)}\right) & \forall w, t, k \in \Omega_{t} \\
C D_{p, k, t} \geq c_{p}^{d}\left(U_{p, \gamma(k),(t-1)}-U_{p, k, t}\right) & \forall p, t, k \in \Omega_{t} \\
\sum_{n} d_{n, k, t}=\sum_{p} G_{p, k, t}+\sum_{w} S_{w, k, t} & \forall p, t, k \in \Omega_{t} \\
+\sum_{j}\left(V_{j, k, t}-W_{j, k, t}\right) &
\end{array}
$$

\footnotetext{
${ }^{8}$ In general, we continue the notation given above. However, due to the stochastic programming approach, the variables are additionally indexed by the set of nodes in the scenario tree $k \subset K$.
} 


$$
\begin{aligned}
& \sum_{n \in \Upsilon(c)} d_{n, k, t}=\sum_{p \in \Psi(\Upsilon(c))} G_{p, k, t}+\sum_{w \in \Psi(\Upsilon(c))} S_{w, k, t} \\
& -\sum_{c c} T_{c, c c, k, t}+\sum_{c c} T_{c c, c, k, t} \\
& +\sum_{j \in \Psi(\Upsilon(c))}\left(V_{j, k, t}-W_{j, k, t}\right) \quad \forall c, t, k \in \Omega_{t} \\
& U_{p, k, t} g_{p}^{\max } \geq G_{p, k, t}+\sum_{r} \overline{R_{p, r, t}^{+}} \quad \forall p, t, k \in \Omega_{t} \\
& G_{p, k, t}-\sum_{r} \overline{R_{p, r, t}^{-}} \geq U_{p, k, t} g_{p}^{\min } \\
& \forall p, t, k \in \Omega_{t} \\
& U_{p, \tilde{k}, \tilde{t}} \geq U_{p, k, t}-U_{p, \gamma(k),(t-1)} \quad \forall p, t, \tilde{t} \in O_{p, t}^{o n} \\
& \forall k \in \Gamma_{\tilde{k}}, \tilde{k} \in \Omega_{\tilde{\tau}} \\
& 1-U_{p, \tilde{k}, \tilde{t}} \geq U_{p, \gamma(k),(t-1)}-U_{p, k, t} \quad \forall p, t, \tilde{t} \in O_{p, t}^{o f f} \\
& \forall k \in \Gamma_{\tilde{k}}, \tilde{k} \in \Omega_{\tilde{\tau}} \\
& L_{j, k, t}=L_{j, \gamma(k),(t-1)}+\eta_{j} W_{j, k, t}-V_{j, k, t} \quad \forall j, t, k \in \Omega_{t} \\
& w_{j}^{\max } \geq W_{j, k, t}+\sum_{r} \overline{R_{j, r, t}^{H-}} \quad \forall j, t, k \in \Omega_{t} \\
& v_{j}^{\max } \geq V_{j, k, t}+\sum_{r} \overline{R_{j, r, t}^{H+}} \quad \forall j, t, k \in \Omega_{t} \\
& l_{j}^{\text {max }} \geq L_{j, k, t}+\sum_{r} \overline{R_{j, r, t}^{H-}} \quad \forall j, t, k \in \Omega_{t} \\
& S_{w, k, t}=\overline{s_{w, k, t}}-C_{w, k, t} \quad \forall w, t, k \in \Omega_{t} \\
& n t c_{c, c c} \geq T_{c, c c, k, t} \quad \forall c, c c, t, k \in \Omega_{t} \\
& G_{p, k, t}, V_{j, k, t}, W_{j, k, t}, L_{j, k, t}, C_{w, k, t}, T_{c, c c, k, t}, C S_{p, k, t}, C D_{p, k, t} \geq 0 \\
& \tilde{G}_{p, k, t}, \tilde{V}_{j, k, t}, \tilde{W}_{j, k, t}, \tilde{C}_{w, k, t} \text { free } \\
& U_{p, k, t} \in\{0,1\}
\end{aligned}
$$

Equations 19 to 22 define the total quantities as the sum of the pre-determined dayahead quantities and the intraday corrective trading actions. Hereby, $\tilde{G}_{p, k, t}$ is the intraday electricity trading amount, which is free in sign, and $G_{p, k, t}$ is the total generation of plant $p$ at the node $k$ in the scenario tree in period $t$. The notation generally follows this reasoning. The remaining (23) to (36) are similar to the corresponding ones in the dayahead model as explained above. Due to the use of the different sets for the expression of the scenario tree, we do not need to impose further non-anticipativity constraints. In equations directly related to the previous period, we make use of the direct predecessor $\gamma(k)$. Furthermore, in the online and offline time requirements, Equations 29 and 30, we use the set of all predecessors in the path to the root node. The periods before the actual period $t$ are denoted by $\tilde{t}$ and the predecessor notes by $\tilde{k}$. 


\subsection{Congestion Management Model}

The congestion management model deals with the management of the physical network constraints and minimizes the costs of generation adjustments in case of overloaded transmission elements. The model builds on the generation levels determined in the previously described dayahead and intraday models. They are given as fixed input parameter to the congestion management model (Kunz 2013; Oggioni et al. 2012). In particular, the congestion management model takes the contracted quantities and the current plant status from the previously solved intraday model. In this stage of the market procedure, we assume that no uncertainty about wind generation is left and that the TSO faces a deterministic problem. Consequently, the TSO readjusts generation level by redispatching operating thermal plants or starting new power plants, such that stability of the transmission network is guaranteed. Moreover, the TSO can apply curtailment of renewable sources if necessary. However, the TSO is not allowed to use storage facilities or to completely shut down thermal power plants. Due to the intertemporal linkage of storage facilities, redispatch actions would feedback to previously determined dayahead and intraday decisions, and are thus excluded from the redispatch. Redispatching variables are labeled by hats and pre-contracted dayahead and intraday quantities are denoted by upper bars, respectively. In general, we follow the notation of the previous model descriptions. However, as the TSO ensures stability for each hour, we drop the time index.

In contrast to the dayahead and intraday models, which consider only international commercial transfers between adjacent countries, the congestion management model incorporates the physical characteristics of transmission flows and technical limitations. A linearized AC-loadflow approach (or DC-loadflow) is utilized to determine physical flows on transmission lines in an existing network (Leuthold et al. 2012). The electricity network is represented by a set of nodes $n \in N$ and lines $l \in L \subset N \times N$ connecting these nodes. Lines are characterized by their thermal capacity $\mathrm{cap}_{l}$. The power transmission distribution factors $p t d f_{l, n}$ determine the flow on line $l$ caused by net injection $Y_{n}$ at node $n$. As already introduced in the dayahead market model, locational information of plants, storage facilities, and renewable sources is expressed using the two-dimensional set $\Psi \subset(P \cup J \cup W) \times N$.

$$
\begin{array}{rlr}
\min & \sum_{p} c_{p} \hat{G}_{p}+\hat{C} S_{p}+\sum_{w} c_{w}^{C} \hat{C}_{w} & \\
G_{p}= & \overline{G_{p}}+\overline{\tilde{G}_{p}}+\hat{G}_{p} & \forall p \\
C_{w}=\overline{C_{w}}+\overline{\tilde{C}_{w}}+\hat{C}_{w} & \forall w \\
\hat{C} S_{p} \geq c_{p}^{s}\left(U_{p}-\overline{\tilde{U}_{p}}\right) & \forall p \\
\sum_{n} d_{n}=\sum_{p} G_{p}+\sum_{w} S_{w} & \\
& +\sum_{j}\left(\bar{V}_{j}+\overline{\tilde{V}}_{j}-\bar{W}_{j}-\overline{\tilde{V}}_{j}\right) &
\end{array}
$$




$$
\begin{array}{rlrl}
d_{n}+Y_{n}= & \sum_{p \in \Psi(n)} G_{p}+\sum_{w \in \Psi(n)} S_{w} & \\
& +\sum_{j \in \Psi(n)}\left(\bar{V}_{j}+\overline{\tilde{V}_{j}}-\bar{W}_{j}-\overline{\tilde{V}_{j}}\right) & & \forall n \\
U_{p} g_{p}^{\max } \geq & G_{p}+\sum_{r} \overline{R_{p}^{+}} & \forall p \\
G_{p}-\sum_{r} \overline{R_{p}^{-}} \geq & U_{p} g_{p}^{\min } & \forall p \\
S_{w}=\overline{s_{w}}-C_{w} & \forall w \\
\operatorname{cap}_{l} \geq \sum_{n} p t d f_{l, n} Y_{n} & \forall l \\
\sum_{n} p t d f_{l, n} Y_{n} \geq & -\operatorname{cap}_{l} \quad & \forall l \\
& & \\
G_{p}, C_{w}, \hat{C} S_{p}, S_{w} \geq 0 & \\
\hat{G}_{p}, \hat{C}_{w}, Y_{n} \text { free } & \\
U_{p} \in\{0,1\} &
\end{array}
$$

The objective function (37) formally describes the costs that are associated with the redispatch of power plants and which would accrue to the transmission system operator. Thus, given the dayahead and intraday results, the model calculates physical line flows and determines cost minimizing redispatch actions if the network is congested. The redispatch costs comprise of two parts (Kunz 2013): power plants that increase their generation $\left(\hat{G}_{p}>0\right)$ get paid their marginal generation cost $c_{p}$; power plants that are asked to decrease their generation level below the contracted market quantities $\left(\hat{G}_{p}<0\right)$ pay their avoided marginal generation cost to the transmission system operator. If the redispatch of thermal generation units is insufficient to ease congestion, the curtailment of wind generation and finally the shedding of load are additional options that are considered in the model. The minimization of the congestion management costs is subject to the constraints (38)-(45), which are comparable to the previous dayahead and intraday market restrictions. Additionally, (46) and (47) limit the physical flows on transmission links to the thermal limit cap $_{l}$.

\subsection{Rolling Planning Procedure}

As described in Section 2 and depicted in Fig. 1, the German electricity market is characterized by a sequential clearing of different markets. In the reserve and dayahead markets, the commitments regarding reserve contribution and generation quantities are determined for all 24 hours of the next day. After the clearing of the dayahead market, intraday trading is possible for each individual hour of the next day starting at 3.00 p.m. the day before and ending 45 minutes before realtime. During this time frame market participants can trade continuously for a specific hour as for instance new information on uncertain parameters (e.g. load, renewable generation, unplanned outages of generation units) become available. 
The described models are designed to reflect these characteristics, in particular the sequential clearing of markets and the improvement of forecasts on uncertain parameters over time. First, the dayahead market model optimizes the generation and reserve commitments for all hours of the next day given the current information on uncertain parameters. The time horizon of the model covers 36 hours comprising 24 hours of the next day and additional 12 hours to account for terminal conditions. Second, the intraday model reoptimizes the dayahead commitments as the information on uncertain parameters improve. The optimized time frame of the intraday model covers 36 hours. However, the intraday model specification abstracts from the market procedure in two ways: first, the intraday model for a specific hour, $t$, is optimized subject to the final realization of uncertain parameters. Thus, the time gap of 45 minutes between the final clearing of the intraday and realtime is neglected. Second, the intraday model abstracts from the continuous trading as the final adjustments of the dayahead commitments for hour $t$ are determined in the intraday optimization of the specific hour $t$, given the improved information on uncertain parameters compared to the dayahead clearing. Furthermore, the future development of uncertain parameters beyond hour $t$ is taken into account by employing a stochastic programming approach. Thus, continuous trading is substituted with centralized intraday clearing. Finally, the congestion management model is optimized after the final clearing of the intraday for the hour $t$, i.e. a single hour is solved.

The sequential clearing of the dayahead and intraday market is achieved by applying a rolling planning procedure. The procedure is initialized by running the dayahead model determining the contracted quantities and reserve contribution for the first 24 hours. For the initialization, generation levels are set to zero and the initial storage level is set to half the storage capacity to give the storage dispatch flexibility in both directions, pumping or generation. Given the values of the first dayahead optimization, we run the intraday model for hour one resulting in the realized generation, storage facility actions, and plant status for hour one. Subsequently, the congestion management model is solved using the previously determined dayahead and intraday generation quantities as starting point. If transmission lines are congested, power plants are redispatched. Moving one hour forward, the intraday and congestion management model are solved again. In this second run we use the plant status as well as the level of the storage facilities of the first run as initial values. Furthermore, status variables are fixed if a startup or shutdown occurred within the previous periods depending on the minimum offline and online times. Having solved the model for hour two, we have the necessary information to solve the intraday and subsequently the congestion management model for hour three. This procedure rolls until hour 12. At hour 12, we first solve the intraday and the congestion management model. From this we obtain the expected value for the plant status, generation, and storage values for the next day hour one. Given these expected values as initial conditions, we solve the dayahead model to determine the precontracted generation quantities and the reserve contribution for day two hour one to 24. This procedure is repeated until the end of the considered time horizon is reached. 


\section{Data}

In order to apply the described model, a dataset of the German electricity system is chosen. The underlying data concerning conventional and renewable generation, electrical load, and the transmission network are described in this section. In addition, the applied wind forecast approach is presented. Wind generation is considered as single source of uncertainty, thus uncertainty resulting from other renewable generation (e.g. photovoltaic), electrical load, and unplanned outages of generation units are neglected. The time horizon used for the application covers the time frame from 4th November until 11th September 2011. The week has been chosen due to the high amount of wind generation and unexpected deviations between expected and final wind generation.

\subsection{Conventional Generation}

We differentiate between dispatchable thermal generation, which is committed and dispatched in the market based on fixed and variable generation costs, and nondispatchable renewable generation characterized by an hourly generation level fed into the system. Thermal generation capacities are based on BNetzA (2012), comprising 411 power plants on block level with a capacity above $20 \mathrm{MW}$. Generation and storage facilities are classified into 12 different technology types reflecting different generation technologies as well as input fuels: run-of-river hydro, nuclear, lignite, coal, gas and oil steam, combined cycle gas (CCGT) and oil turbines plants (CCOT), open cycle gas (OCGT) and oil turbines plants (OCOT), hydro reservoirs, and pump storage plants. The technical characteristics of conventional generation technologies, including heat efficiency, minimum generation, emission factor, and minimum online and offline time, are summarized in Table 1.

Table 1 Technical characteristics of thermal generation types

\begin{tabular}{|c|c|c|c|c|c|}
\hline & $\begin{array}{l}\text { Average } \\
\text { Efficiency } \\
{[\%]}\end{array}$ & $\begin{array}{l}\text { Minimum } \\
\text { Generation } \\
{[\%]}\end{array}$ & $\begin{array}{l}\text { Emission } \\
\text { Factor } \\
{\left[\mathrm{t} \mathrm{CO}_{2} / \mathrm{MWh}(\mathrm{el})\right]}\end{array}$ & Ontime & Offtime \\
\hline Nuclear & 30 & 45 & 0 & 12 & 8 \\
\hline Lignite & 37 & 40 & 0.98 & 8 & 8 \\
\hline Hard Coal & 42 & 38 & 0.85 & 8 & 8 \\
\hline CCGT & 54 & 33 & 0.37 & 4 & 2 \\
\hline OCGT & 34 & 20 & 0.59 & 1 & 0 \\
\hline Gas Steam & 39 & 38 & 0.52 & 4 & 2 \\
\hline CCOT & 50 & 33 & 0.56 & 4 & 2 \\
\hline OCOT & 34 & 20 & 0.82 & 1 & 0 \\
\hline Oil Steam & 39 & 38 & 0.71 & 4 & 2 \\
\hline
\end{tabular}

Bagemihl (2003), IPCC (2006), Hundt et al. (2009), and own assumptions 
Table 2 Economic characteristics of thermal generation types

\begin{tabular}{llll}
\hline & $\begin{array}{l}\text { Fuel Cost } \\
{[\text { EUR/MWh] }}\end{array}$ & $\begin{array}{l}\text { Marginal Cost } \\
{[\text { EUR/MWh] }}\end{array}$ & $\begin{array}{l}\text { Startup Cost } \\
\text { [EUR/startup and MW] }\end{array}$ \\
\hline Nuclear & 3 & 9.71 & 60 \\
Lignite & 4.39 & 24.58 & 87 \\
Hard Coal & 13.14 & 42.50 & 86 \\
CCGT & 29.60 & 59.44 & 114 \\
OCGT & 29.60 & 94.75 & 43 \\
Gas Steam & 29.60 & 82.61 & 188 \\
CCOT & 43.61 & 94.42 & 163 \\
OCOT & 43.61 & 138.86 & 58 \\
Oil Steam & 43.61 & 121.06 & 275 \\
\hline
\end{tabular}

Statistik der Kohlenwirtschaft (2013), DEWI, EON Netz, EWI, RWE Transportnetz Strom, VE Transmission (2005), and own assumptions

Average fuel and carbon emission certificate prices in 2011 are used to determine the plant specific generation cost structure, consisting of marginal generation and fixed startup costs. The marginal costs are derived from the fuel costs, which are given in Table 2, and the carbon costs based on a carbon price of $12.94 \mathrm{EUR} / \mathrm{t} \mathrm{CO} 2$. Both cost components are accounted for with a power plant specific heat efficiency, which increases in the commissioning year of the power plant (Schröter 2004). In addition to the marginal generation costs, fixed startup costs capturing the increased fuel consumption during the startup process are defined for each technology type following (DEWI, EON Netz, EWI, RWE Transportnetz Strom, VE Transmission 2005). Shutdown costs are assumed to be zero.

\subsection{Renewable Generation}

Renewable generation is considered as non-dispatchable, facing an hourly feed-in pattern that is determined based on historical generation values for the considered time horizon of one week. Electricity production from wind turbines, photovoltaic $(\mathrm{PV})$, and biomass units is regarded as renewable generation, of which wind is considered, in this study, to be uncertain. Generation from PV and biomass are reflected by a deterministic historical production pattern.

To account for uncertainty of renewable wind generation, the model uses three different inputs: first, the hourly realization of renewable generation; second, the corresponding daily dayahead forecast, which enters the dayahead model; and finally, a set of renewable generation scenarios, which are considered in the intraday model using a scenario tree. The realized hourly generation values as well as the daily dayahead forecasts are taken from the EEX Transparency Platform ${ }^{9}$ and are depicted in

${ }^{9}$ http://www.transparency.eex.com/en, accessed January 24, 2014 


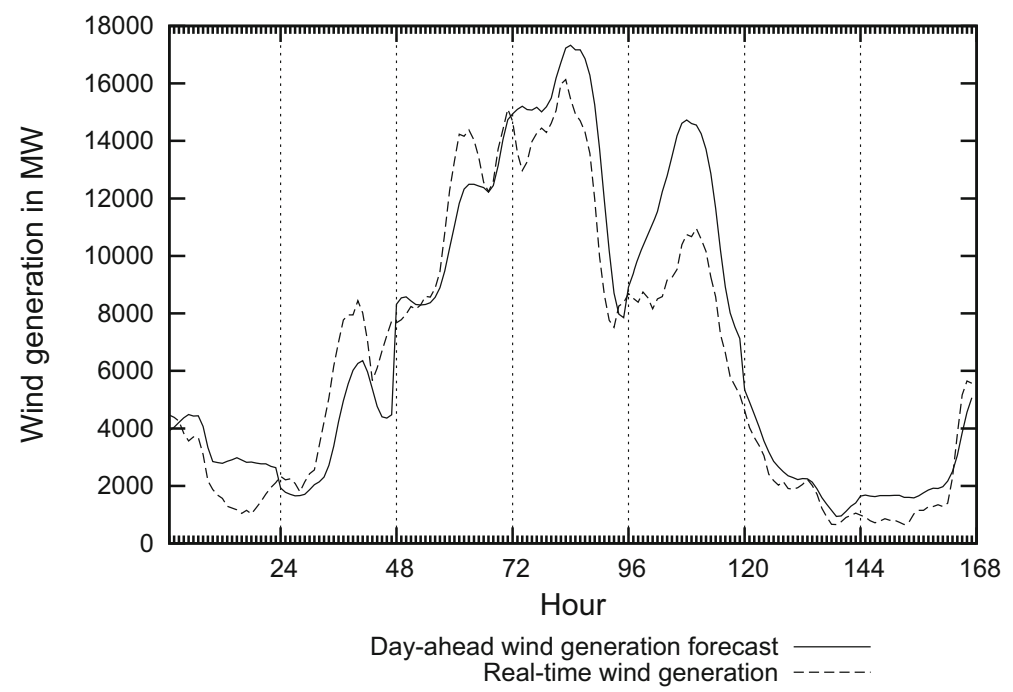

Fig. 2 Expected and realized wind generation in Germany from 4th until 11th September 2011. Source: EEX Transparency Platform

Fig. 2 for the considered week. Within this week, renewable generation contributes, on average, $13 \%$ to electrical load with a maximum of $25 \mathrm{GW}$ reflecting $32 \%$ of electrical load. Additionally, it can be seen in Fig. 2 that wind generation experiences high forecast errors between dayahead and real-time with an average absolute deviation of $1.3 \mathrm{GW}$. The highest forecast deviation amounts to $4.6 \mathrm{GW}$ or $6 \%$ of electrical load.

In order to incorporate the uncertainty of renewable wind generation within the stochastic modeling setup, a set of forecasts that generally describes the uncertainty of renewable generation increasing in the length of forecasting time is specified. Thus, for each time point we simulate a separate set of candidate forecasts for the following time periods, i.e. 36 hours, to account for the fact that forecasts improve closer to real-time. The set of forecasts or candidate scenarios is then reduced to a representative set of six scenarios, which finally enters the stochastic intraday model. We first describe the generation of our candidate scenarios, followed by the applied reduction approach.

As we build on the historical realized renewable generation, we explicitly simulate a set of forecast errors instead of explicit generation forecasts. They are afterwards added to the realized wind generation. The simulation approach uses an auto regressive moving average (ARMA) approach for the wind speed errors (Barth et al. 2006) that is defined as follows:

$$
W_{f t}^{e r r}=\alpha W_{f t-1}^{e r r}+Z_{f t}+\beta Z_{f t-1}
$$

where $W_{f t}^{e r r}$ is the forecast error for time period $f t$ and $Z_{f t}$ is a random Gaussian variable with a standard deviation of $\sigma$. For $f t=0$, the forecast error $W_{f t=0}^{e r r}$ and the 


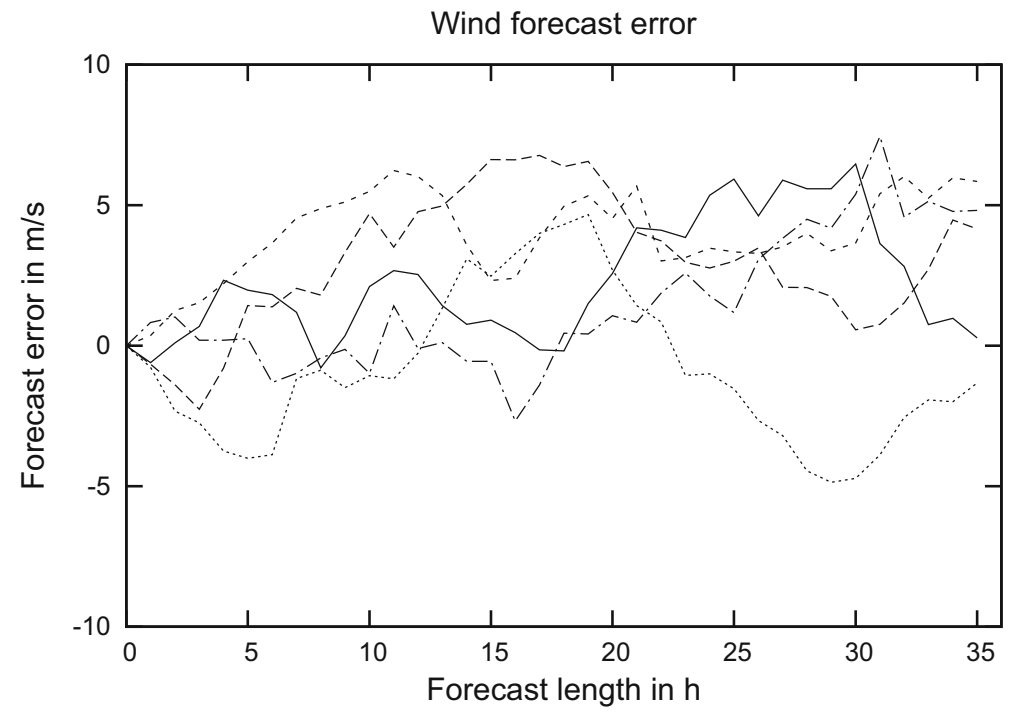

Fig. 3 Exemplary set of simulated wind speed forecast errors

random variable $Z_{f t=0}$ are zero, as we already know the final realization. If we look into the future $(f t>0)$ the forecast error depends firstly on the forecast error of the previous period and, secondly, on a stochastic component. This yields a forecast error increasing in forecast length, as illustrated in Fig. 3. The parameters of the ARMAseries $\alpha$ and $\beta$ are assumed to be 0.98 and -0.7 , respectively. The standard deviation $\sigma$ is set to 0.4 . These values are defined to resemble statistical data on forecast quality for Germany (Borggrefe and Neuhoff 2011). Finally, we simulate for each time point 100 scenarios for 36 hours in advance and weight each scenario equally, i.e. $1 \%$.

Once candidate forecast errors are simulated, they are added to the realized hourly generation patterns for each time point. In order to incorporate the set of simulated generation series in the stochastic modeling approach, a two-stage scenario tree is implemented consisting of one root node for the first realization time point and a tree node for each future time point and scenario. Thus, for a time horizon of 36 hours and 100 scenarios, we end up with 3501 scenario tree nodes. Thus, considering the initial set of simulated scenarios would increase computational complexity significantly. Therefore, we employ the reduction algorithm, described in Dupačová et al. (2003), Heitsch and Römisch (2003) and implemented in the scenario reduction software SCENRED $2{ }^{10}$, to obtain a reduced set of six scenarios, which is computationally manageable within an acceptable time frame. We finally end up with a two-stage scenario tree consisting of 211 nodes (see Fig. 4).

Finally, we need to distribute national renewable generation derived from the scenario reduction approach to individual substations within the transmission network. For this purpose, regional data on renewable power installations provided from

\footnotetext{
${ }^{10}$ http://www.gams.de/dd/docs/solvers/scenred2.pdf, accessed June 6, 2013
} 


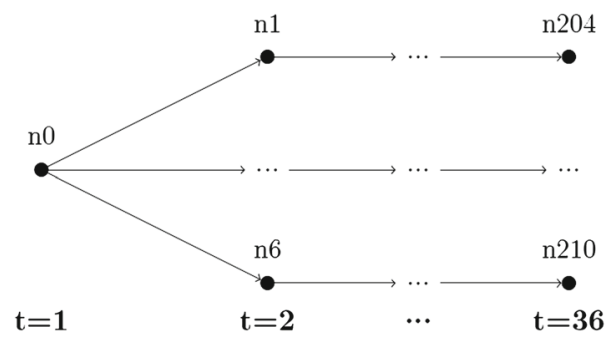

Fig. 4 Scenario tree representation

50Hertz Transmission, Amprion, TransnetBW, TenneT TSO (2012) is used as proxy for regional renewable generation. Hence, we implicitly assume full correlation of regional renewable generation.

\section{$3.3 \mathrm{Load}$}

Electrical load represents the hourly consumption of electricity by households, services, and industry connected to the transmission grid, as well as exports to neighboring countries. The hourly load profile is derived from (ENTSO-E 2014) for the considered week from 4th until 11th September 2011. As we focus on the short-term hourly operation of the electricity system, we assume a fixed and price-inelastic load, which does not react to real-time market prices. This is mainly reasoned by a lack of real-time metering and billing in most load segments. ${ }^{11}$ Furthermore, we assume a deterministic load pattern and thus abstract from any load uncertainty.

Given the national load profile, a nodal load pattern is required for transmission network calculations. For this purpose, regional information on gross domestic product (GDP) and population are taken into account to distribute the national load profile to transmission network nodes (Leuthold et al. 2012). The regional GDP serves as a distribution proxy for electrical load of industry and services, whereas the regional population is used for households, respectively. The regional GDP and population are taken from Eurostat (2011) on a NUTS 3 level, ${ }^{12}$ corresponding to districts in Germany.

\subsection{Transmission Network}

The focus of our analysis is on the German high-voltage transmission network comprising of transmission lines and substations with a voltage level of $220 \mathrm{kV}$ and $380 \mathrm{kV}$. The topology of the transmission network is based on ENTSO-E (2012)

\footnotetext{
${ }^{11}$ Moreover, incorporating a price-sensitive load through a load curve requires, firstly, the specification of the load curve type (e.g. affine or exponential) and sensitive parameters (e.g. elasticity). Secondly, it increases complexity and reduces solvability of the unit commitment models due to the introduction of non-linear elements. See e.g. De Jonghe et al. (2014) for an application of price responsive load.

${ }^{12}$ NUTS (Nomenclature of Territorial Units for Statistics) is a hierarchical system for geographic division of the European territory.
} 
and contains 342 substations and 866 transmission circuits. The transmission grid is depicted in Fig. 5. Technical characteristics of transmission circuits (resistance, reactance, thermal limit) are based on Kießling et al. (2001). For voltages of $380 \mathrm{kV}$ and $220 \mathrm{kV}$, the specific values for reactance $\left(x_{l}\right)$ and resistance $\left(r_{l}\right)$, accounted with the length of individual transmission lines and the topology of the entire network, provides the basis for the calculation of the power transfer distribution matrix (PTDF, $\left.p t d f_{l, n}\right)$. The PTDF specifies the utilization of a transmission line by a particular nodal injection for a given network topology. Finally, the available transmission capacity $\left(\mathrm{cap}_{l}\right)$ reflects the specific thermal transmission limit derated by $20 \%$ to account for $\mathrm{N}-1$ security requirements.

\section{Results}

\subsection{Cases}

In the illustrative application of the model, we consider a benchmark case abstracting from both uncertainty about renewable generation as well as the daily market clearing

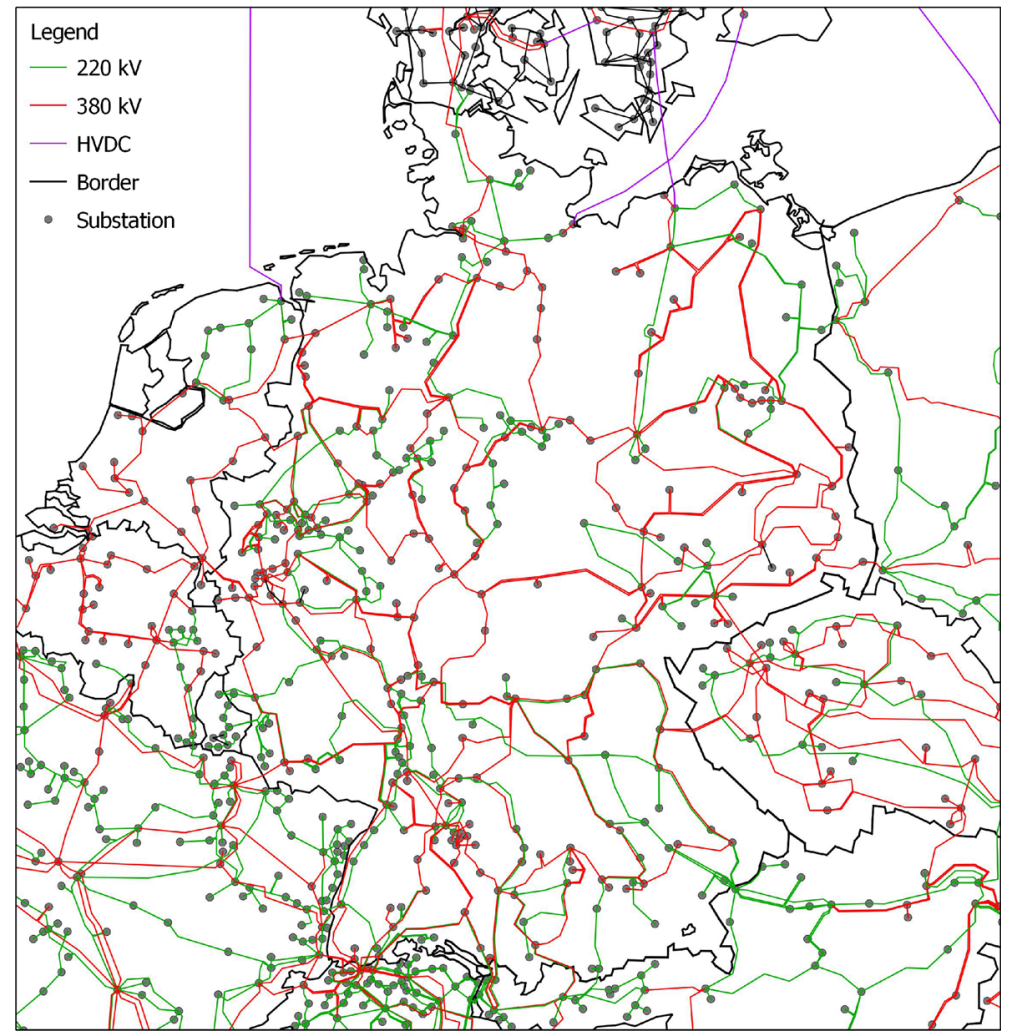

Fig. 5 Topology of the German high-voltage transmission grid 
structure. Moreover, we formulate three additional cases that include the daily market procedure and different approaches to incorporate intermittent renewable generation.

The Integrated setup serves as the benchmark case. It determines the cost-minimal generation commitment and dispatch over the entire model horizon under perfect information and taking into account the physical constraints of the electricity transmission grid. In particular, the Integrated approach neglects the subsequent clearing of dayahead and intraday markets, and treats the problem as if the system operator would take decisions at the beginning of the time horizon for all future periods given the deterministic generation from renewable sources.

The Deterministic case relies on a deterministic renewable generation schedule, but employs the rolling planning approach comprising subsequent dayahead and intraday markets as well as the congestion management. In each model iteration, the future generation of renewable sources is known for certain for a specified time horizon, i.e., for the next 36 hours. However, no information beyond the covered time horizon is included. Consequently, as the model steps forward in time, subsequent iterations reveal new information about electrical load and renewable supply for the newly added hours.

The Changing Forecast case also uses the rolling planning approach, but uncertainty of renewable generation is introduced. A unique forecast is taken into account in the dayahead market, whereas the intraday decision is based on the expected value of renewable energy supply. The expected value is calculated as the probability weighted sum of renewable generation forecasts defined in the scenario tree. In each iteration, this expected value changes as the forecasts on renewable generation are revised. Moreover, the forecast error declines as the time gap between the hour of decision making and the hour of realization decreases. As in the Deterministic scenario, each iteration reveals additional load and renewable information for the added hour. However, this new information is an expected value that changes with each subsequent iteration.

The Stochastic case extends the previous case and applies stochastic programming approach for the intraday decision. In contrast to the Changing Forecast scenario, the decision is based on the scenario tree that approximates the distribution of renewable generation underlying the expected value. Thus, the first stage has perfect foresight, whereas a set of scenarios is considered for later stages. As in the other two approaches, the rolling planning procedure implies that in each iteration additional information are revealed regarding the renewable supply and load in the hour newly added. However, this new information is a scenario tree that approximates the distribution of renewable generation and changes in each subsequent iteration. ${ }^{13}$

Each of the cases is solved for a total time frame of nine days. The first and the last day are introduced to account for initial and terminal model conditions. In particular, the first day is characterized by high system operating costs as the entire system has to be initialized. Consequently, the reported time horizon covers one week of seven days. Regarding model statistics, the integrated deterministic

\footnotetext{
${ }^{13}$ The expected value of the approximated distribution is always equal to the expected value used in the Changing Forecast case.
} 
model, covering the total time frame of nine days, has a size of 1,864,546 equations and 1,505,281 variables including 89,040 binary variables. In the rolling planning approach, the stochastic model comprises 666,262 equations and 605,284 variables of which 46,721 are binary variables, and is solved for each hour with a modeling horizon of 36 hours. The model is coded in GAMS and was solved with the CPLEX mixed integer solver with a high performance computing cluster using four $2.9 \mathrm{GHz}$ CPUs and $15 \mathrm{~GB}$ RAM. The solution precision was set to a tolerance gap of $0.01 \%$. The solution time for the considered time frame amounted 1 hour for the deterministic and 11 hours for stochastic model version.

\subsection{Results}

In this section, we present the results for the German electricity system covering one week. We first analyze the implications of the rolling planning approach by comparing the integrated and the deterministic case. Both cases assume perfect foresight, but differ in the considered time horizon for optimization. As can be seen in Table 3, the integrated case features lower total system costs than the deterministic case that considers dayahead and intraday markets linked by a rolling planning. Comparing the dayahead costs, the introduction of the rolling planning procedure increases the system costs by $2.3 \%$. Through the incorporation of an hourly cleared intraday market cost reductions can be realized stemming from the adjustment of previously determined dayahead commitments. As the dayahead market is optimized for a limited time horizon of 36 hours, the determined generation schedules are optimal with respect to this time frame. However, for the entire time frame of one week, dayahead schedules are less optimal and thus reoptimization of generation is beneficial. This is highlighted by the strong decrease of startup costs that are realized in the intraday market. Finally, the management of network congestion arising from determined market schedules is required. Transmission lineflows are accordingly changed to stay within transmission limits through increasing and decreasing generation at different locations in the network. These redispatch actions come at certain costs as the generation of less expensive operating plants are replaced by more expensive

Table 3 Cost Results of the integrated and deterministic case [Mill. Euro]

\begin{tabular}{lcc}
\hline & Integrated & Deterministic \\
\hline Dayahead & 243.9 & 249.5 \\
Fuel & 173.0 & 172.9 \\
Carbon & 68.6 & 69.1 \\
Startup & 2.2 & 7.5 \\
Intraday & & -4.5 \\
Fuel & & 0.3 \\
Carbon & & -0.2 \\
Startup & & -4.7 \\
Redispatch & 243.9 & 0.4 \\
Total & & 245.3 \\
\hline
\end{tabular}




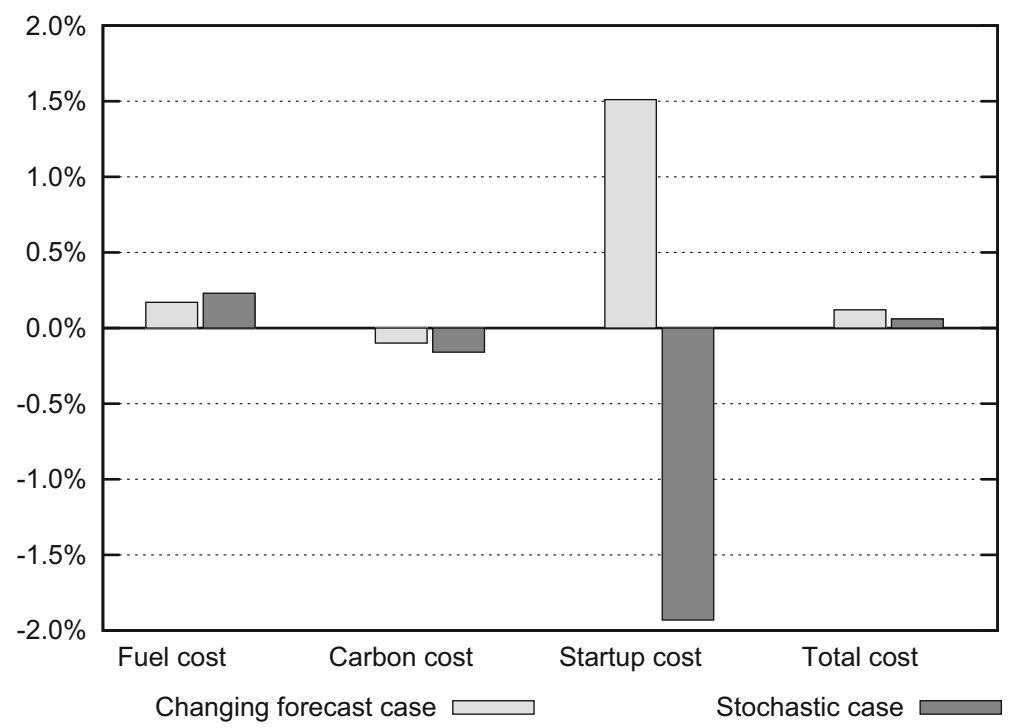

Fig. 6 Change in cost compared to the deterministic case

generation units. The integrated case already optimizes the network usage in the dayahead model, reflecting a nodal pricing regime. In the end, the deterministic case shows $0.6 \%$ higher total system costs than the integrated optimization approach. The cost advantage follows, firstly, from a higher utilization of baseload generation, which replaces more costly coal-fired midload generation in off-peak periods, and, secondly, from lower peakload and accordingly increased flexible midload generation in peak times. Moreover, it is important to note that the intraday market is particularly important as it allows for a reoptimization of the generation schedules.

Beyond the impact of rolling planning approach, different cases of accounting for uncertain renewable wind generation are considered. In the following, we evaluate their implications on system costs, generation, and network usage by comparing stochastic approaches with the deterministic case.

Figure 6 depicts the percentage change in total system costs as well as the different cost components. Generally, an increase of total cost is observed with the introduction of intermittent wind generation. For the considered time frame of one week, generation costs increase by $0.1 \%$ in the changing forecast and $0.04 \%$ in the stochastic case compared to perfect foresight. Moreover, both cases show an increase of fuel costs and a decrease of carbon costs due to the fact that inflexible coal-fired generation is replaced with more flexible gas units (Fig. 7) ${ }^{14}$. Thus, the flexibility of generation portfolio is improved through this shift of generation, which causes higher generation costs. However, the changing forecast and the stochastic case differ in their choice of

\footnotetext{
${ }^{14}$ Conventional generation technologies are grouped into baseload (nuclear, lignite), midload (hard coal), flexible midload (CCGT), and peakload (OCGT, gas steam, CCOT, OCOT, oil steam, and pumped-hydro storage).
} 


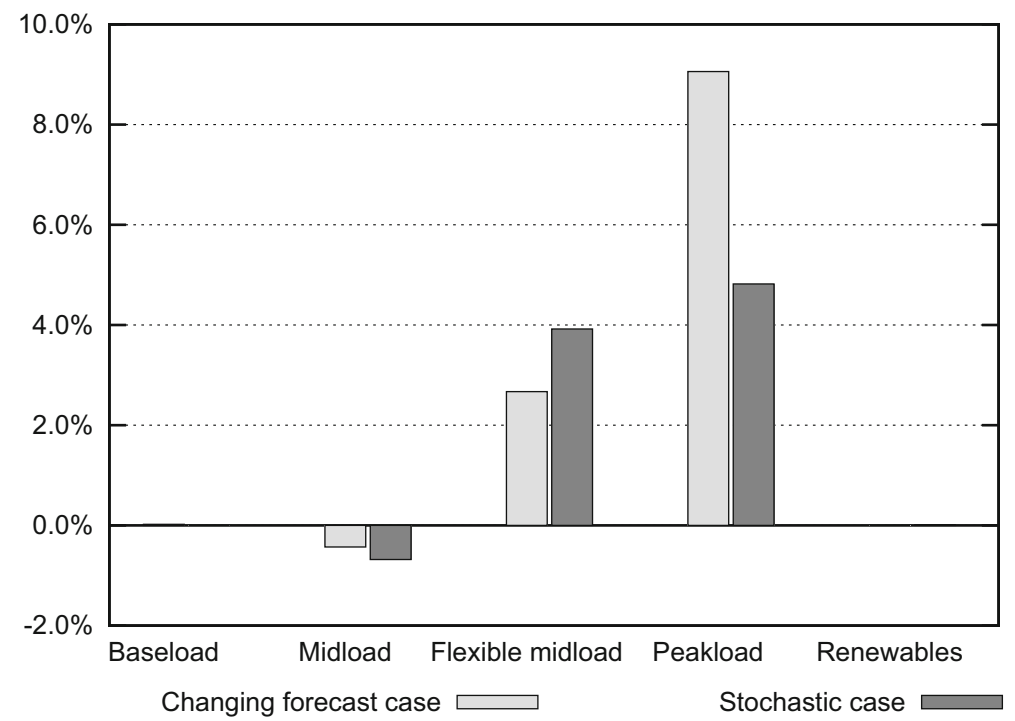

Fig. 7 Change in generation compared to the deterministic case

flexibility options. The changing forecast approach utilizes more peakload generation than the stochastic case, which uses flexible midload units to deal with intermittent renewable generation. As the changing forecast optimizes deterministically given a single forecast, deviations are mainly absorbed by flexible peaking units that are able to fast startup. This results in higher startup costs than in other cases as can be seen in Fig. 6. In contrast to this, startup costs are substantially lower in the stochastic approach. As this case takes a set of forecast scenarios into account, the generation commitment is optimized to be able to cope with different wind situations. This results in lower startups and, consequently, lower associated costs (Fig. 6). Moreover, the average number of operating plants is higher in the stochastic optimization as a consequence of lower startup costs. This is depicted in Fig. 8. It can be seen that the average number of total operating plants is higher in both cases compared to the deterministic approach. Moreover, the changing forecast case makes use of flexible midload and peakload units, whereas the stochastic case additionally utilizes less flexible midload generation, which is operated under part-load conditions. This yields lower total system cost in the stochastic case compared to the approach with a single renewable forecast, but higher costs than the deterministically optimized case.

However, overall cost changes between the considered cases are small, which implies that the uncertainty about renewable feed-in is absorbed by the electricity system without significant effects given regularly updated renewable forecasts and the possibility of intraday trading. Furthermore, the analysis reveals that the technical flexibility of conventional generation fleet is sufficient to deal with the current level of intermittent renewable wind generation. However, the cases differ in the way flexibility of conventional generation is improved.

Regarding the implications on the network level, congestion management costs indicate the ability of the generation mix to be changed in case of situations with 


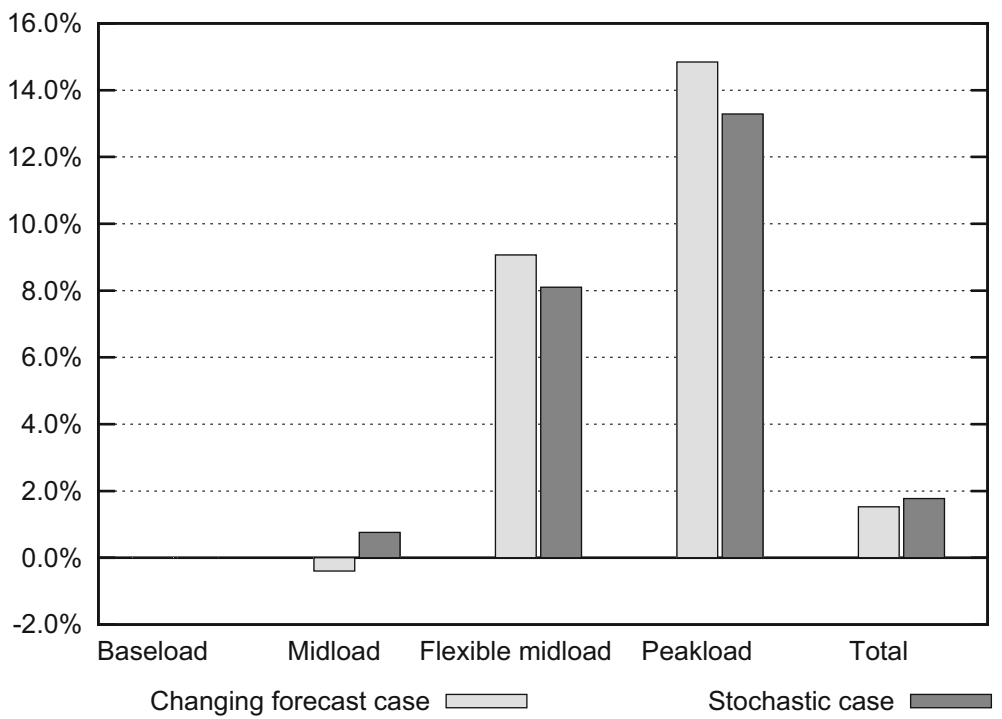

Fig. 8 Change in average number of operating plants compared to the deterministic case

network congestion. Thus, redispatch costs can be seen as an indicator for flexibility of the operating generation fleet. Compared to the deterministic case, the changing forecast yields higher redispatch costs (approx. $+18 \%$ ), whereas costs are lowered by approx. $7 \%$ in the stochastic case. Hence, through the stochastic optimization approach, more generation units are operating at part-load, which gives the transmission system operator a higher degree of flexibility for resolving line congestion. Consequently, congestion management costs decline as more coal-fired generation can be redispatched instead of more costly gas-fired units. Moreover, Fig. 9 depicts a histogram of the percentage change of average line utilization. Generally, the overall network utilization decreases slightly by roughly $0.1 \%$ in the changing forecast case, and increases by $0.1 \%$ in stochastic case, compared to perfect foresight. Thus, overall effects are rather small, but particular lines show substantial changes in their utilization as shown in Fig. 9. Average utilization of approx. $20 \%$ of transmission lines is changed by more than $4 \%$ in the stochastic case, and slightly less in the changing forecast case. Single lines are affected even more, up to $20 \%$ change of average utilization compared to a deterministic optimization. This implies that the way how uncertainty of renewable generation is treated imposes different requirements for the transmission network which is caused by differences in the generation commitment and dispatch.

To this end, our analysis reveals that the impact of intermittent renewable wind generation depends on the way uncertainty is treated in the modeling approach. It is shown that for the current German power system, uncertainty does not imply substantial changes of total system costs, but that the uncertainty is compensated by an increase of flexibility of the generation portfolio. Moreover, this impacts the network utilization and the congestion in the transmission network. However, it is important 


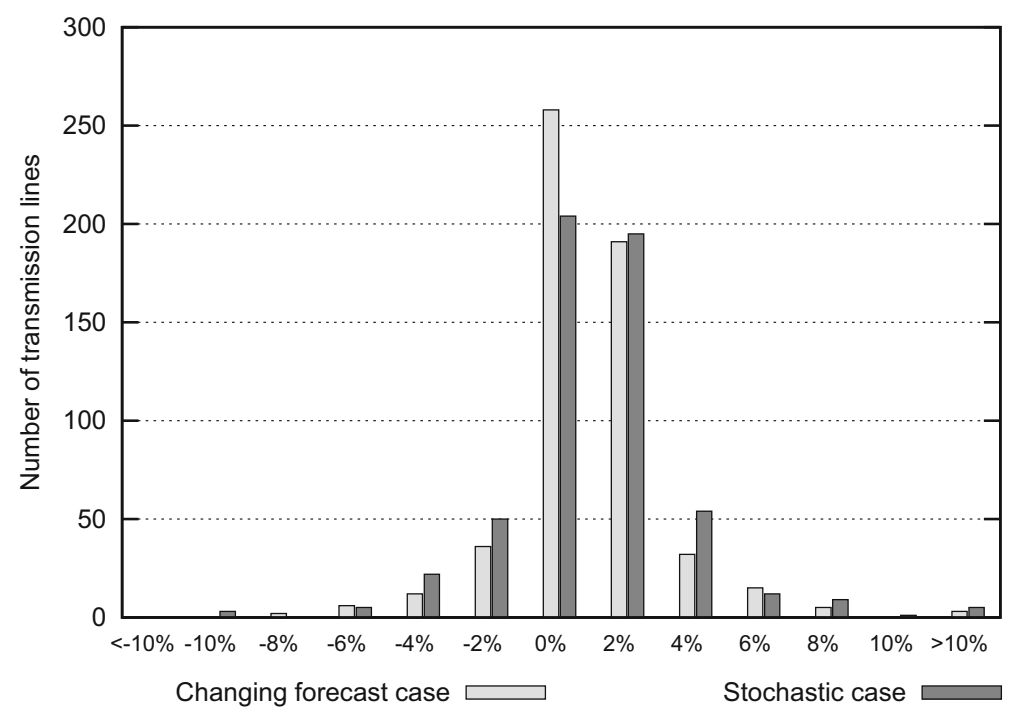

Fig. 9 Change in average line utilization compared to the deterministic case

to note that the results reflect the German power system and are not generally applicable to other regions with a different conventional generation portfolio. Moreover, the influence of uncertainty changes with differing assumptions on the uncertain parameter.

In a sensitivity analysis we evaluate the impact of, firstly, the magnitude of wind penetration by doubling the wind generation and, secondly, of its variability. The impact of the wind variability is tested by doubling the variance of wind power, but leaving the mean of the distribution as well as the realized wind generation unchanged compared to the initial setup. By doubling the mean of the distribution and the final realization, but holding the variance constant, we examine the influence of a higher magnitude of wind generation. Figure 10 depicts the impact of these changes on system costs compared to the corresponding perfect foresight case.

Figure 10 reveals that the relative cost ranking of the different approaches remains unchanged: the deterministic optimization shows the lowest total costs followed by the stochastic programming approach which shows lower overall costs than the changing forecast case. Interestingly, overall cost changes of the stochastic case with doubled wind generation are reduced compared to the deterministic version. This is caused by the fact that more baseload generation, i.e., nuclear and lignite, is operated at part-load due to increased wind generation, and used for intraday corrections. Moreover, the increase of wind variability results in higher costs for both cases which is caused by an increased utilization of flexible peaking unit to compensate short-term fluctuations. Summing up, the effect of the wind variability has greater impacts on costs than the wind generation level as a higher technical flexibility of the generation portfolio is required. Through a stochastic approach, cost reductions are realizable due to the consideration of different possible renewable generation scenarios in the commitment and dispatch optimization. 


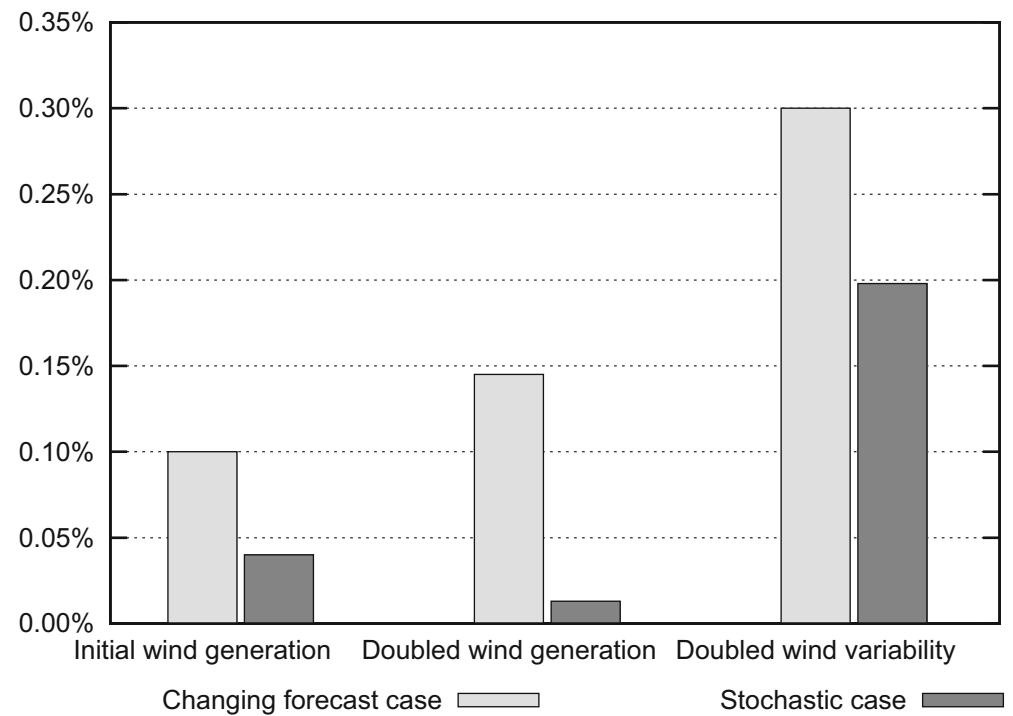

Fig. 10 Change in total system cost compared to the deterministic case

\section{Conclusions}

In this paper the stochastic electricity market model stELMOD, which captures the economic and technical characteristics of liberalized electricity markets, is described. First the unit commitment and generation dispatch for the following day is determined in a dayahead market model. Simultaneously capacities providing reserves for system stability are optimized. Afterwards, an hourly intraday market model enables the adjustment of dayahead generation quantities as well as the unit commitment if required. Uncertainty about wind generation is incorporated and successively updated to reflect the improvement of wind generation forecast over time. Finally network constraints are reflected using a DC-loadflow approach that captures the physical characteristics of transporting electrical energy. Possible applications of the model are to analyze the impact of stochastic renewable generation or the impact of different markets regimes within the rolling planning procedure on electricity market results. Future analysis could also address the issue of the optimal timing of electricity markets within a daily market procedure.

In an illustrative application to the German power system, we compare different approaches of dealing with the uncertainty about wind generation in an integrated benchmark that optimizes over the entire time horizon, under perfect information. Introducing the current system of subsequent dayahead and intraday markets followed by a congestion management stage leads to an increase in the total system costs. This cost increase occurs independently of whether wind generation is considered to be stochastic or not. The introduction of intermittent wind generation either in the form of changing expected forecasts or by a changing distribution further increases system costs. The use of stochastic programming leads to lower 
costs than the expected value optimization as the stochastic programming approach avoids startup costs by operating less flexible generation technologies under part-load conditions.

\section{A Nomenclature}

Indices

$\Gamma(k)$

$\gamma(k)$

$\Psi$

A

$J, j$

$K, k$

$L, l$

$N, n$

$O_{p, t}^{o f f}, O_{p, t}^{o n}$

$P, p$

$R, r$

$T, t$

$W, w$

Parameters

$\frac{\eta_{j}}{s_{w, t}}$

$\pi_{k}$

$b_{l, n}$

$B_{n, n n}$

$c_{w}^{c}$

$c_{p}^{s}, c_{p}^{d}$

$c_{p}$

capl $_{l}$

$d_{n, t}$

$d r_{c, r, t}^{+}, d r_{c, r, t}^{-}$

$g_{p}^{\max }, g_{p}^{\min }$

$H_{l, n}$

$l_{j}^{\max }$

$p t d f_{l, n}$

$r_{l}$

$t_{p}^{o n}, t_{p}^{o f f}$

$v_{j}^{\max }$

${ }_{j}^{\max }$

$w_{j}^{\max }$

$x_{l}$
All predecessors of scenario tree node $k$

Direct predecessor of scenario tree node $k$

Mapping from power plants to nodes

Set of power plants allowed to contribute to reserve $r$

Set of pump storage facilities

Set of nodes in the stochastic tree

Set of lines

Set of nodes in electricity network

Minimum offline and ontime periods

Set of power plants

Set of reserve markets

Set of time periods

Set of renewable sources

Pump storage efficiency of pump storage $j$

Expected renewable supply

Probability of occurrence of scenario tree node $k$

Incidence matrix

Nodal susceptance matrix

Curtailment cost of renewable source $w$

Startup and shutdown cost of power plant $p$

Marginal cost of power plant $p$

Line capacity of line $l$

Load at node $n$

Upward and downward reserve load

Maximum and minimum generation of power plant $p$

Branch susceptance matrix

Maximum storage level of pump storage $j$

Power transfer distribution factor

Series reactance of line $l$

Required online and offline times of power plant $p$

Maximum pump storage release of pump storage $j$

Maximum pump storage pumping of pump storage $j$

Series resistance of line $l$ 
Variables

Upper bars denote variables fixed in the respective model. Tilde denotes intraday and hat congestion management variables.

$\begin{array}{ll}C_{w, t} & \text { Curtailment of renewable generation } w \\ C S_{p, t}, C D_{p, t} & \text { Startup and shutdown cost of power plant } p \\ G_{p, t} & \text { Generation of power plant } p \\ L_{j, t} & \text { Storage level of pump storage } j \\ R_{p, t}^{+}, R_{p, t}^{-} & \text {Provided upward and downward reserve of power plant } p \\ R_{j, t}^{H+}, R_{j, t}^{H-} & \text { Provided upward and downward reserve by pump storage } j \\ S_{w, t} & \text { Supply of renewable generation } w \\ T_{c, c c, t} & \text { Commercial transfer between country } c \text { and } c c \\ U_{p, t} & \text { Operating status of power plant } p \text { (One if plant is on, otherwise zero) } \\ V_{j, t} & \text { Generation of pump storage } j \\ W_{j, t} & \text { Loading of pump storage } j \\ Y_{n, t} & \text { Netinput from the transmission grid at node } n\end{array}$

Acknowledgments Friedrich Kunz acknowledges financial support of the Mercator foundation and the RWE fellowship program (RWE Studienförderung). The authors thank Christian von Hirschhausen and Hannes Weigt for comments.

\section{References}

50Hertz Transmission, Amprion, TransnetBW, TenneT TSO (2012). EEG Anlagenstammdaten. http:// www.netztransparenz.de/de/Anlagenstammdaten.htm

Abrell J, Weigt H (2012) Combining energy networks. Netw Spat Econ 12(3):377-401

Bagemihl J (2003) Optimierung eines Portfolios mit hydro-thermischem Kraftwerkspark im börslichen Strom- und Gasterminmarkt. PhD thesis, Institute of Energy Economics and the Rational Use of Energy, University of Stuttgart, URL http://elib.uni-stuttgart.de/opus/volltexte/2003/1387/pdf/ bagediss_gesamt.pdf

Baldick R (1995) The generalized unit commitment problem. IEEE Trans Power Syst 10(1):465-475. doi: $10.1109 / 59.373972$

Barth R, Söder L, Weber C, Brand H, Swider DJ (2006) Wilmar Deliverable 6.2 (d)- Methodology of the Scenario Tree Tool, Documentation. Tech. rep., Institute of Energy Economics and the Rational Use of Energy, University of Stuttgart. http://www.wilmar.risoe.dk/

Birge JR, Louveaux F (1997) Introduction to Stochastic Programming. Springer-Verlag Inc, New York

BNetzA (2012) List of Power Plants. http://www.bundesnetzagentur.de/cln_1932/EN/Areas/ ElectricityGasRegulation/SpecialTopics/PowerPlantList/PubliPowerPlantList_node.html; jsessionid=79D374DC200620EB705734DCE17E6361, Bundesnetzagentur (BNetzA)

Borggrefe F, Neuhoff K (2011) Balancing and intraday market design: Options for wind integration. DIW Discussion Paper 1162, URL http://www.diw.de/sixcms/detail.php?id=diw_01.c.387259.de

Bouffard F, Galiana FD (2008) Stochastic security for operations planning with significant wind power generation. IEEE Trans Power Syst 23(2):306-316. doi:10.1109/TPWRS.2008.919318

Conejo A, Carrión M, Morales J (2010) Decision making under uncertainty in electricity markets, vol 153. Springer Verlag

De Jonghe C, Hobbs BF, Belmans R (2014) Value of price responsive load for wind integration in unit commitment. IEEE Trans Power Syst 29(2):675-685

Devine MT, Gleeson JP, Kinsella J, Ramsey DM (2014) A rolling optimisation model of the uk natural gas market. Netw Spat Econ 14(2):209-244 
DEWI, EON Netz, EWI, RWE Transportnetz Strom, VE Transmission (2005) Energiewirtschaftliche Planung fur die Netzintegration von Windenergie in Deutschland an Land und Offshore bis zum Jahr 2020. Tech. rep., German Energy Agency (dena), Berlin, Germany, URL http://www.dena.de/ fileadmin/user_upload/Download/Dokumente/Projekte/ESD/netzstudie1/dena-Netzstudie_l.pdf

Dupačová J, Gröwe-Kuska N, Römisch W (2003) Math Program 95:493-511. doi:10.1007/ s10107-002-0331-0

ENTSO-E (2012) Entso-e grid map. https://www.entsoe.eu/resources/grid-map/, European Network of Transmission System Operators for Electricity (ENTSO-E)

ENTSO-E (2014) Consumption data. https://www.entsoe.eu/resources/data-portal/consumption/, European Network of Transmission System Operators for Electricity (ENTSO-E)

Eurostat (2011) Regional statistics. http://epp.eurostat.ec.europa.eu/portal/page/portal/region_cities/ regional_statistics/data/database, Statistical Office of the European Union

EWEA (2011) Wind in power - 2010 European statistics. Tech. rep., European Wind Energy Association (EWEA), http://www.ewea.org/fileadmin/ewea_documents/documents/statistics/EWEA_Annual_ Statistics_2010.pdf

Habis H, Csercsik D (2014) Cooperation with externalities and uncertainty. Netw Spat Econ

Heitsch H, Römisch W (2003) Scenario reduction algorithms in stochastic programming. Comput Optim Appl 24:187-206. doi:10.1023/A:1021805924152

Hundt M, Barth R, Sun N, Wissel S, Voß A (2009) Verträglichkeit von erneuerbaren Energien und Kernenergie im Erzeugungsportfolio- Technische und ökonmische Aspekte. Tech. rep., E.On Energie AG, Munich, Germany

IPCC (2006) 2006 IPCC Guidelines for National Greenhouse Gas Inventories, Volume 2 Energy. http:// www.ipcc-nggip.iges.or.jp/public/2006gl/pdf/2_Volume2/V2_2_Ch2_Stationary_Combustion.pdf, Intergovernmental Panel on Climate Change

Jonkeren O, Azzini I, Galbusera L, Ntalampiras S, Giannopoulos G (2014) Analysis of critical infrastructure network failure in the european union: A combined systems engineering and economic model. Networks and Spatial Economics

Kall P, Wallace SW (1994) Stochastic programming. John Wiley \&amp Sons, Chichester

Kallrath J, Pardalos PM, Rebennack S, Scheidt M (eds) (2009) Optimization in the energy industry. Springer-Verlag, Berlin

Kießling F, Nefzger P, Kaintzyk U (2001) Freileitungen - Planung, Berechnung, Ausführung. Springer, Berlin

Kunz F (2013) Improving congestion management - how to facilitate the integration of renewable generation in Germany. Energ J 34(4):55-78

Leuthold F, Weigt H, von Hirschhausen C (2009) When the Wind Blows Over Europe - A Simulation Analysis and the Impact of Grid Extensions. Dresden University of Technology, Chair of Energy Economics, Electricity Market Working Paper WP-EM-31. http://www.ee2.biz

Leuthold F, Weigt H, von Hirschhausen C (2012) A large-scale spatial optimization model of the European electricity market. Netw Spat Econ 12(1):75-107

Metzler C, Hobbs BF, Pang JS (2003) Nash-cournot equilibria in power markets on a linearized dc network with arbitrage: Formulations and properties. Netw Spat Econ 3(2):123-150

Möst D, Keles D (2010) A survey of stochastic modelling approaches for liberalised electricity markets. Eur J Oper Res 207(2):543-556. doi:10.1016/j.ejor.2009.11.007

Neuhoff K, Barquin J, Bialek J, Boyd R, Dent C, Echavarren F, Grau T, von Hirschhausen C, Hobbs BF, Kunz F, Nabe C, Papaefthymiou G, Weber C, Weigt H (2013) Renewable electric energy integration: quantifying the value of design of markets for international transmission capacity. Energ Econ 40:760-772

Oggioni G, Smeers Y, Allevi E, Schaible S (2012) A generalized nash equilibrium model of market coupling in the european power system. Netw Spat Econ 12:503-560. doi:10.1007/s11067-011-9166-7

Padhy NP (2004) Unit commitment-a bibliographical survey. IEEE Trans Power Syst 19(2):1196-1205. doi:10.1109/TPWRS.2003.821611

Papavasiliou A, Oren SS (2013) Multiarea stochastic unit commitment for high wind penetration in a transmission constrained network. Oper Res 61(3):578-592. doi:10.1287/opre.2013.1174. http:// pubsonline.informs.org/doi/abs/10.1287/opre.2013.1174

Pritchard G, Zakeri G, Philpott A (2010) A single-settlement, energy-only electric power market for unpredictable and intermittent participants. Oper Res 58(4-part-2):1210-1219. doi:10.1287/opre.1090.0800 
Ruiz PA, Philbrick CR, Zak E, Cheung KW, Sauer PW (2009) Uncertainty management in the unit commitment problem, vol 24, pp 642-651. doi:10.1109/TPWRS.2008.2012180

Schröter J (2004) Auswirkungen des europischen Emissionshandelssystems auf den Kraftwerkseinsatz in Deutschland. Master's thesis, Technische Universität Berlin, Institut für Energietechnik, Fachgebiet Energiesysteme, http://www.ensys.tu-berlin.de/uploads/media/schroeter_2004_ auswirkungen_co2_zertifikatehandel.pdf

Spiecker S, Weber C (2014) The future of the european electricity system and the impact of fluctuating renewable energy a scenario analysis. Energ Policy 65:185-197

Statistik der Kohlenwirtschaft (2013) Entwicklung ausgewählter Energiepreise. http://www. kohlenstatistik.de/files/enpr.xlsx

Traber T, Kemfert C (2011) Gone with the wind? - electricity market prices and incentives to invest in thermal power plants under increasing wind energy supply. Energy Econ 33:240-259

Tuohy A, Meibom P, Denny E, O'Malley M (2009) Unit commitment for systems with significant wind penetration. IEEE Trans Power Syst 24(2):592-601. doi:10.1109/TPWRS.2009.2016470

Wallace SW, Fleten SE (2003) Stochastic Programming Models in Energy, Handbooks in Operations Research and Management Science, vol 10, chap 10. Elsevier, Amsterdam, pp 637-677

Wang J, Shahidehpour M, Li Z (2008) Security-constrained unit commitment with volatile wind power generation. IEEE Trans Power Syst 23(3):1319-1327. doi:10.1109/TPWRS.2008.926719

Wang J, Botterud A, Bessa R, Keko H, Carvalho L, Issicaba D, Sumaili J, Miranda V (2011) Wind power forecasting uncertainty and unit commitment. Appl Energy 88(11):4014-4023. doi:10.1016/j.apenergy.2011.04.011

Weber C (2005) Optimization in the electric power industry: methods and models for decision support. Springer, Boston

Weber C, Meibom P, Barth R, Brand H, Pardalos PM, Kallrath J, Pardalos PM, Rebennack S, Scheidt M (2009) Wilmar: A stochastic programming tool to analyze the large-scale integration of wind energy. Springer, Berlin, pp 437-458

Weigt H, Jeske T, Leuthold F, von Hirschhausen C (2010) Take the long way down: Integration of largescale North Sea wind using HVDC transmission. Energy Policy 38(7):3164-3173

van der Weijde AH, Hobbs BF (2012) The economics of planning electricity transmission to accommodate renewables: Using two-stage optimisation to evaluate flexibility and the cost of disregarding uncertainty. Energy Econ 34:2089-2101 